\title{
APLICAÇÃO DA NORMA DE INSPEÇ̃̃O PREDIAL NACIONAL (IBAPE) EM EDIFICAÇÕES POPULARES - ESTUDO DE CASO: CURVELO-MG
}

\author{
GEOVANA TEIXEIRA SOUZA, ISABELA \\ Estudante de graduação \\ CEFET-MG - Curvelo \\ Minas Gerais; Brasil \\ isabela_tsouza@yahoo.com
}

\author{
DE PAULO RAMOS, MARCOS \\ Professor EBTT \\ CEFET-MG - Curvelo \\ Minas Gerais; Brasil \\ marcos.ramos@cefetmg.br
}

\author{
MARTINI, RACHEL \\ Professora EBTT \\ CEFET-MG - Curvelo \\ Minas Gerais; Brasil \\ martini@cefetmg.br
}

\author{
COTA GUEDES, FLÁVIA \\ Estudante de graduação \\ CEFET-MG - Curvelo \\ Minas Gerais; Brasil \\ flavia_cota@hotmail.com \\ PENA BORTONE, THIAGO \\ Professor EBTT \\ CEFET-MG - Curvelo \\ Minas Gerais; Brasil \\ thiago.bortone@ cefetmg.br
}

\author{
FERREIRA, LUCIANA \\ Professora EBTT \\ CEFET-MG - Curvelo \\ Minas Gerais; Brasil \\ lupiferreira@cefetmg.br
}

\section{RESUMO}

Frequentemente em residências unifamiliares de baixa renda, as especificações normativas não são devidamente observadas, podendo causar deficiências no projeto e na execução. Essa questão, aliada à inexistência de manutenção, má qualidade dos materiais utilizados ou causas externas, levam ao surgimento de falhas e anomalias construtivas que se manifestam de diferentes formas, comprometendo a segurança e a durabilidade da edificação. $O$ presente trabalho tem como objetivo realizar a inspeção predial em edificações populares utilizando a Norma de Inspeção Predial Nacional do IBAPE. Para o seu desenvolvimento, na primeira etapa foi realizada uma detalhada pesquisa bibliográfica. $\mathrm{Na}$ segunda etapa, realizou-se a inspeção predial em uma edificação popular de forma a identificar as falhas e as anomalias. Na terceira etapa, foi elaborado o laudo de inspeção predial. Na última etapa, determinaram-se as possíveis medidas corretivas, além da conscientização do proprietário da importância da adequada manutenção.

Palavras-chave: Patologia, inspeção predial, residências unifamiliares.

\begin{abstract}
Often in low-income single-family homes, normative specifications are not properly observed which may cause deficiencies in design and execution. This issue, coupled with the lack of maintenance, poor quality of materials used or external causes, lead to the emergence of constructive failures that manifest themselves in different ways, compromising the safety and durability of the building. The present work aims to perform the building inspection in popular buildings using the IBAPE National Building Inspection Standard. For its development, in the first stage a detailed bibliographic research was performed. In the second stage, the building inspection was performed in a popular building in order to identify the constructive failures and anomalies. In the third stage, the building inspection report was prepared. In the last stage, possible corrective measures were determined, as well as the owner's awareness of the importance of proper maintenance.
\end{abstract}

Keywords: Pathology, building inspection, single-family homes. 


\section{INTRODUÇÃO}

De acordo com a Câmara de Inspeção Predial do IBAPE/SP (2012), os sistemas construtivos, para garantir desempenho e segurança, demandam manutenção ao longo de sua vida útil. Essa manutenção é um meio de prevenir e diminuir a degradação da edificação.

Conforme a Norma de Inspeção Predial Nacional (2012, p.5), do Instituto Brasileiro de Avaliações e Perícias de Engenharia - IBAPE, inspeção predial é "a análise isolada ou combinada das condições técnicas, de uso e de manutenção da edificação". Segundo Neves e Branco (2009), a inspeção predial analisa as condições físicas de um imóvel, avaliando seu desempenho, o tempo de vida útil, seu estado de conservação e manutenção. Outro papel importante é o auxílio em transações imobiliárias, pois o laudo de inspeção predial exterioriza, quantifica e classifica, de acordo com o grau de risco, todas as anomalias da edificação dando mais clareza sobre as reais condições físicas do imóvel.

O presente trabalho consistiu na realização da inspeção predial em uma edificação habitacional de baixa renda, onde realizou-se a verificação das condições técnicas de uso e de manutenção da edificação, visando orientar a manutenção e a qualidade predial, seguindo os requisitos da Norma de Inspeção Predial Nacional do IBAPE. O início dos trabalhos de inspeção predial advém do rápido processo de deterioração que estava acontecendo em obras de artes especiais e pavimentos e começou após o acontecimento de acidentes ou falhas (NOGUEIRA, 2003). Nos EUA foi a American Association of State Highway and Transportation Officials (AASTHO) a responsável por elaborar o primeiro manual de inspeção em pontes (FREEBAY, 2013). Esse processo de inspeção disseminou-se para outras áreas como a de residências, mostrando ser promissor e eficiente.

Segundo Pacheco (2017) e Neves e Branco (2009) no Brasil, a terminologia Inspeção Predial foi apresentada pela primeira vez no ano de 1999, no X Congresso Brasileiro de Avaliações e Perícias de Engenharia - COBREAP. De acordo com Neves e Branco (2009) dois anos depois do congresso o IBAPE/SP lançou a primeira norma técnica. Segundo Pacheco (2017) essas iniciativas foram um grande avanço uma vez que, no Brasil, ainda não existe uma norma regulamentora publicada pela Associação Brasileira de Normas Técinicas (ABNT). Atualmente, existe um projeto de norma denominado ABNT NBR 16747 - Inspeção Predial - Procedimentos e Terminologia que já passou pela Consulta Nacional e em breve será publicada, tornando oficial, por parte da ABNT, os procedimentos a serem adotados para tal atividade. Contudo, apesar de ainda não haver tal norma da ABNT específica para o procedimento de inspeção predial, a norma ABNT NBR 14037 - Diretrizes para elaboração de manuais de uso, operação e manutenção das edificações Requisitos para elaboração e apresentação dos conteúdos, é a responsável por estabelecer os requisitos necessários para elaboração do manual de uso, operação e manutenção de uma edificação.

\section{METODOLOGIA DE INSPEÇÃO EM EDIFICAÇÕES}

O principal indicador de eficiência do gerenciamento de manutenção é o atendimento aos requisitos descritos na norma Desempenho de Edificações Habitacionais, NBR 15575, que trata das características de desempenho de uma edificação habitacional (ABNT, 2013).

Toda edificação exige intervenções periódicas durante o seu tempo de vida útil para que continue atendendo aos requisitos de desempenho exigidos pela NBR 15575, de acordo com seu uso (SILVA, 2016). Edificações em que não ocorrem essas intervenções, ou manutenções, podem vir a sofrer com a degradação precoce de suas partes e perda de desempenho ocasionadas por má qualidade dos materiais ali usados e/ou deficiências no projeto (POSSAN; DEMOLINE, 2013). A norma de Manutenção de Edificações, NBR 5674 (ABNT,2012), define manutenção como atividades realizadas periodicamente para preservar as características da edificação e prevenir a perda de desempenho devido à deterioração dos seus sistemas e elementos.

Ainda segundo essa norma, cada edificação deve possuir um programa de manutenção específico, o qual deve ser atualizado periodicamente. Este programa precisa conter considerações sobre o projeto, memoriais e manuais de uso, além de particularidades como a tipologia e uso efetivo da edificação, idade e expectativa de durabilidade da construção e seus sistemas, relatórios de vistorias já realizadas, incluindo relatos das não conformidades encontradas e histórico de manutenções já executadas, tudo isso visando à maximização da vida útil da edificação e à eliminação de possíveis gastos com a recuperação da estrutura. 
Com a manutenção adequada, a edificação recupera parte do nível de desempenho perdido devido à deterioração natural dos seus componentes com o tempo, como mostra o gráfico da Figura 1.

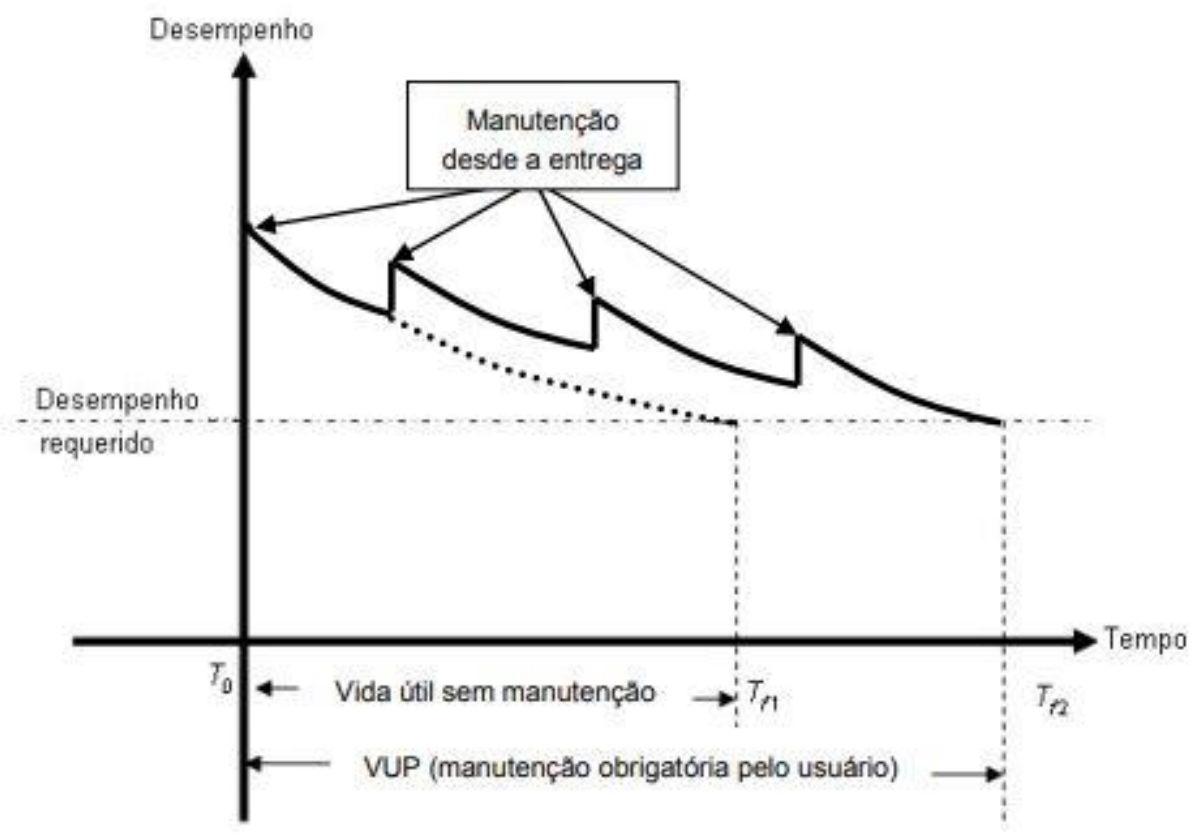

Figura 1: Desempenho ao longo do tempo.

Fonte: NBR 15575 (ABNT, 2013).

Como supracitado, o programa de manutenção solicita inspeções prediais periódicas e elaboração de seus respectivos laudos. As inspeções prediais são norteadas pela norma de inspeção nacional do IBAPE e para se avaliar as condições de uma edificação é normalmente utilizado o método de inspeção visual. Segundo Silva (2016), esta inspeção se limita às partes visíveis dos sistemas e elementos, eximindo aqueles aos quais não se pode ter acesso, que não estejam visíveis ou nos quais exista qualquer limitação que impeça sua verificação. Como este método não conta com ensaios laboratorias ou mesmo de campo, se vale principalmente da percepção e experiência do profissional responsável, devendo ser executado com análise observacional criteriosa.

A metodologia de inspeção definida na norma consiste nas seguintes etapas: determinação do nível de inspeção, de acordo com o tipo e complexidade da edificação; análise de documentos de ordem técnica, administrativa e de manutenção; levantamento de informações junto aos usuários; vistoria dos elementos constantes no check list, previamente elaborado; classificação das anomalias encontradas quanto à origem e quanto ao grau de risco; elaboração de uma lista de prioridades, ordenada em função do grau de risco; recomendações técnicas para sanar os efeitos das anomalias; avaliação da manutenção e uso, de acordo com o plano de manutenção da edificação inspecionada; recomendações quanto ao uso dos recursos e preservação da segurança e conforto dos moradores; e por fim, a elaboração do laudo contendo todos os pontos especificados pela norma (IBAPE, 2012).

\section{ESTUDO DE CASO}

O foco deste trabalho são residências unifamiliares de baixa renda, portanto a residência escolhida pertence a uma família que recebeu o auxílio do Governo Federal no programa Minha Casa Minha Vida (MCMV). Trata-se de uma residência com idade de sete anos, localizada no município de Curvelo-MG.

O que motivou o estudo foi a percepção de que em construções como esta, muitas vezes não é dada a devida importância às normas pertinentes, e não raramente, são construídas sem o adequado acompanhamento por profissional qualificado. Além de sofrerem com más práticas de construção, são também erguidas com materiais de qualidade inferior, fatores que levam ao surgimento de manifestações patológicas em um curto espaço de tempo após a entrega da obra. 
Em construções em massa como é o caso das casas do programa MCMV, apesar de muitas vezes serem executadas por grandes construtoras, a intensa repetição dos processos pode levar a erros de execução, o que também ocasiona anomalias construtivas com o passar do tempo. Como se trata de moradias para população de baixa renda, para se alcançar a redução desejada no preço, a solução é diminuir o tamanho e muitas vezes a qualidade de cada unidade (NOVELLO, 2018).

De acordo com Apolonio, Bertulino e Lins (2017), em uma fiscalização realizada pelo Ministério da Transparência, habitações populares construídas no período de 2011 a 2014 pelo programa MCMV apresentaram cerca de $50 \%$ de falha. Ainda segundo os autores, o portal de notícias online UOL, noticiou em 2017, que o maior conjunto habitacional de Manaus, foi alvo de inspeções pela Defensoria Pública do Estado do Amazonas, cujo laudo detectou diversas anomalias nas residências.

Romero e Ornstein (2003) enaltecem que essas avaliações de rotina podem melhorar a satisfação dos clientes, já que as falhas construtivas e de uso podem ser amenizadas. Como observado, casas unifamiliares de baixa renda precisam ter um controle de anomalias que seja rotineiro e contínuo para que não ocasione grandes problemas futuramente.

\section{METODOLOGIA DE ESTUDO}

A metodologia empregada segue os requisitos prescritos pela norma de inspeção predial nacional do IBAPE. O método de vistoria adotado neste estudo foi a inspeção visual, e antes de se dar início ao processo foi realizada uma breve entrevista com os usuários da edificação com o objetivo de conhecer as anomalias e falhas construtivas já constatadas por eles, bem como informar como funciona o processo de inspeção e a sua importância. Além disso, foram solicitados todos os projetos e documentos relativos ao imóvel.

A etapa seguinte consistiu no registro fotográfico de todos os detalhes da edificação onde foram evidenciadas as anomalias e falhas construtivas. Concomitantemente, foi feita a documentação escrita dos itens inspecionados para compor o check list de inspeção.

Foram analisados todos os elementos da parte externa e interna do imóvel, a começar pela fachada e calçada, onde foram verificados itens como caixa de esgoto e dutos de escoamento de água pluvial. Na parte interna do imóvel e no interior da edificação foram verificados os muros, a estrutura e a cobertura, bem como, os revestimentos externo e interno; parte das instalações elétricas foram testadas e as partes visíveis das instalações hidráulicas também foram verificadas.

Após a checagem de todos os itens constantes no check list, foi dado início à elaboração do laudo de inspeção que, segundo cartilha formulada pelo IBAPE-SP, não se trata apenas de um relatório, e sim de um documento técnico contendo todas as etapas do trabalho realizado (IBAPE, 2015). Compõem este laudo todos os dados da edificação pertinentes ao caso, lista dos documentos obtidos e analisados, anomalias e falhas encontradas, assim como as classificações destas, registros fotográficos, recomendações técnicas e todos os demais itens exigidos pela norma referente. O referido laudo foi entregue ao proprietário, juntamente com exposição verbal dos principais problemas encontrados e algumas recomendações sobre manutenções preventivas e corretivas visando eliminar suas manifestações e conscientizar os moradores da importância da inspeção predial periódica e da manutenção de sua residência.

\subsection{Elaboração do Laudo}

A metodologia utilizada na elaboração do laudo é baseada na norma de inspeção predial nacional do IBAPE, onde se analisou o risco da edificação decorrente do uso e exposição ao ambiente, e consiste na classificação das anomalias verificada nos diversos componentes quanto ao seu grau de Gravidade, de Urgência, e de Tendência (metodologia técnica denominada GUT / Ferramenta de "gerenciamento de risco"), relacionado com fatores de conservação, depreciação, saúde, segurança e funcionalidade dos sistemas constituintes.

O processo de gerenciamento dos riscos envolve as ações de identificação dos sistemas a serem protegidos; levantamento dos riscos naturais, acidentais e causados por pessoas; identificação das vulnerabilidades e impactos; determinação das probabilidades de ocorrência das ameaças; estimativa dos prejuízos dos impactos; tratamento dos riscos com respectivas medidas; monitoração das medidas; e reavaliação periódica dos riscos. 
Identificadas as anomalias, a ordem em que devem ser abordadas sob os pontos de vista do sistema GUT (Gravidade/Urgência/Tendência), adaptado da metodologia de Kepner e Tregoe para a manutenção predial, é determinada através da aplicação de pesos, em função de sua criticidade, de acordo com a seguinte tabela (KEPNER e TREGOE, 1981 apud DIAS et al, 2018):

Tabela 1 - Pesos para classificação do grau Gravidade, Urgência e Tendência.

\begin{tabular}{c|c|c}
\hline Grau & Gravidade & Peso \\
\hline Total & Perda de vidas humanas, do meio ambiente ou do próprio edifício & 10 \\
\hline Alta & Ferimentos em pessoas, danos ao meio ambiente ou ao edifício & 8 \\
\hline Média & Desconfortos, deterioração do meio ambiente ou do edifício & 6 \\
\hline Baixa & Pequenos incômodos ou pequenos prejuízos financeiros & 3 \\
\hline Nenhuma & Nenhuma & 1 \\
\hline Grau & Urgência & Peso \\
\hline Total & Evento em ocorrência & 10 \\
\hline Alta & Evento prestes a ocorrer & 8 \\
\hline Média & Evento prognosticado para breve & 6 \\
\hline Baixa & Evento prognosticado para adiante & 3 \\
\hline Nenhuma & Evento imprevisto & 1 \\
\hline Grau & Tendência & Peso \\
\hline Total & Evolução imediata & 10 \\
\hline Alta & Evolução em curto prazo & 8 \\
\hline Média & Evolução em longo prazo & 6 \\
\hline Baixa & Fonte: Diaso em médio prazo al (2018). & 3 \\
\hline
\end{tabular}

Fonte: Dias et al (2018).

\section{RESULTADOS E DISCUSSÕES}

\subsection{Análise das principais anomalias encontradas}

Nesta seção serão apresentadas as principais anomalias encontradas, sendo estas: manchas de infiltração, oxidação das esquadrias, oxidação de peças da cobertura e manifestações patológicas nas paredes (trincas e infiltrações). 


\section{CBPAT 2020 \\ CONGRESSO BRASILEIRO DE PATOLOGIA DAS CONSTRUÇÕES \\ DE 15 A 17 DE ABRIL | FORTALEZA - CE}

ISBN 978-65-86819-05-2

\subsubsection{Manchas de infiltração}

A Figura 2 mostra manchas características de infiltração encontradas na parte externa da casa.

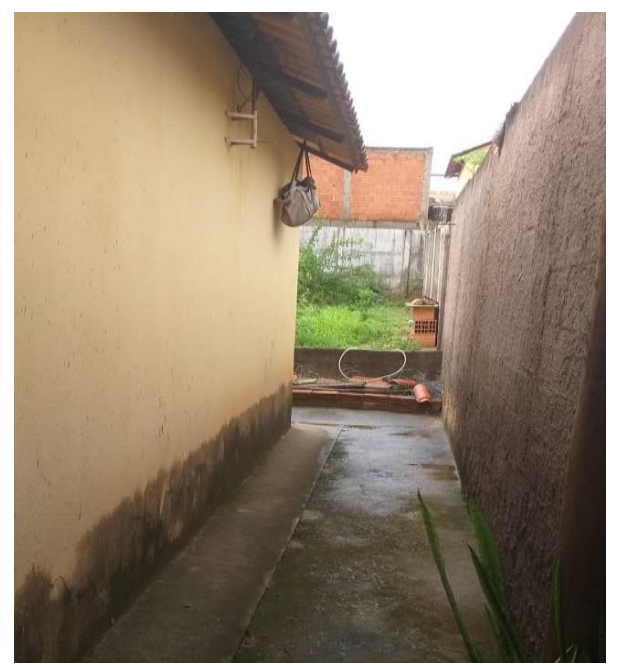

(a)

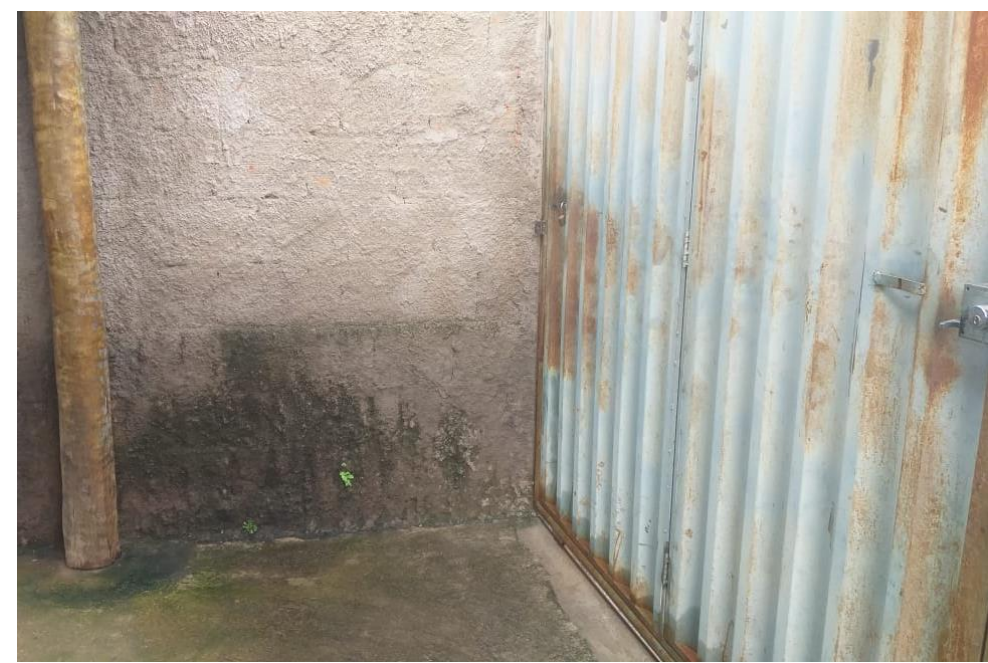

(b)

Figura 2: (a) Infiltração na parede externa lateral; (b) Infiltração no muro de divisa.

Fonte: Acervo fotográfico dos autores.

Detectaram-se sinais de umidade constante na parte lateral da casa, através de manchas características na parede lateral e no muro. Devido ao nível do terreno ao lado ser mais alto que o da casa e não ter sido feito nenhuma impermeabilização para a construção do muro, são encontradas manchas de umidade em todo o muro que faz a divisa.

\subsubsection{Oxidação do portão}

Na Figura 3 é possível ver a oxidação do portão de entrada/garagem da residência.

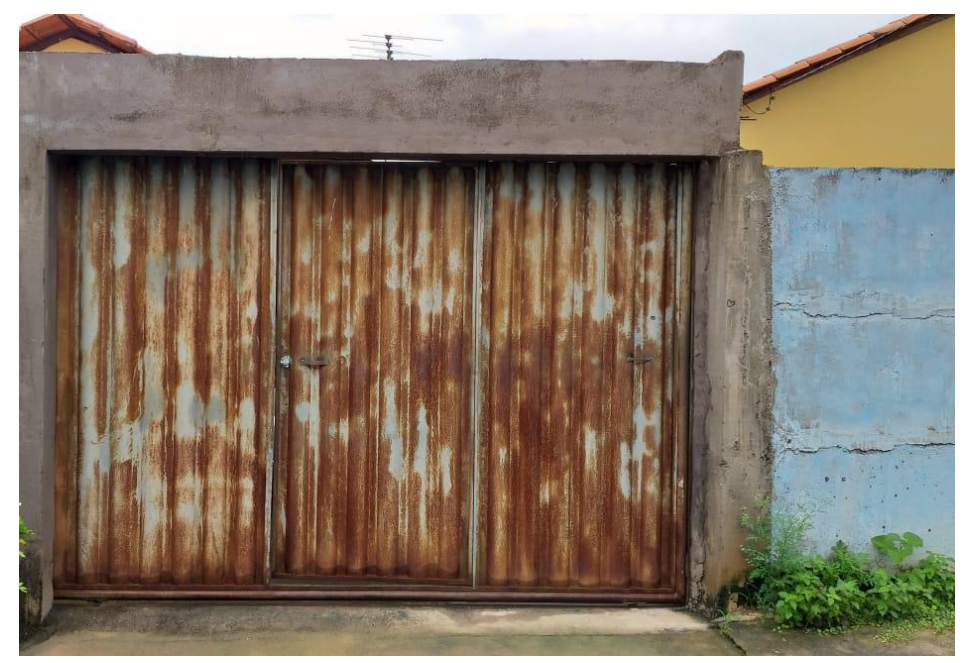

Figura 3: Oxidação no portão de metal.

Fonte: Acervo fotográfico dos autores.

O enfurrujamento do portão foi ocasionado pela falta de pintura. Por se tratar de uma região com clima predominantemente seco, o material (metalon) ainda não apresenta sinais de intensos de perda de seção do por oxidação. 


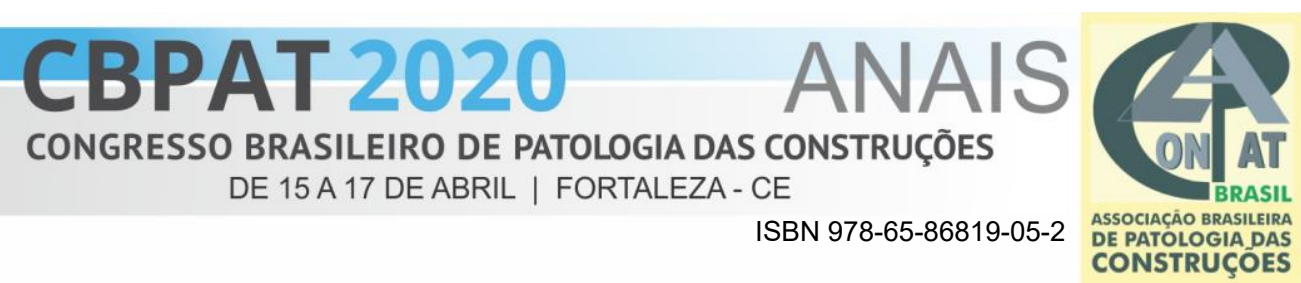

\subsubsection{Oxidação das terças}

A Figura 4 traz a oxidação encontrada nas peças da cobertura da habitação.

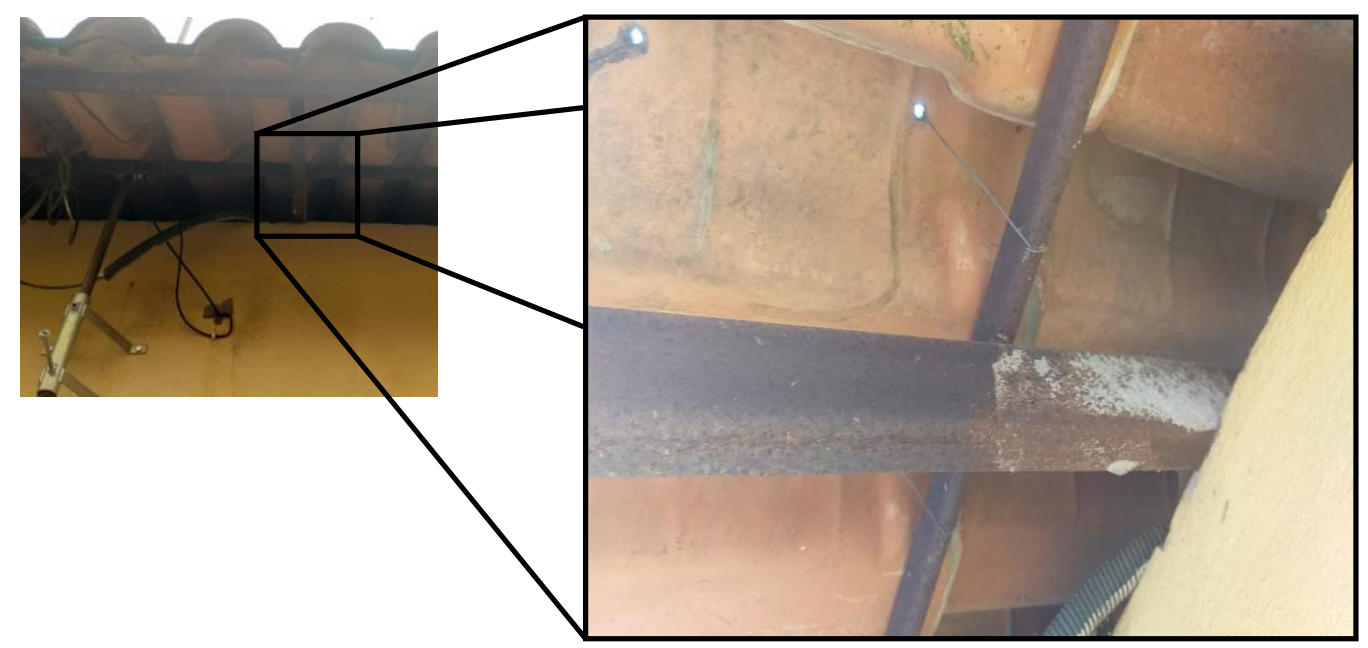

Figura 4: Projeção lateral do telhado com detalhe da oxidação encontrada nas terças. Fonte: Acervo fotográfico dos autores.

A cobertura da casa foi construída em estrutura metálica, porém os elementos não foram pintados, motivo pelo qual foi observado processo de oxidação.

\subsubsection{Trincas na parede do corredor}

As trincas da parede podem ser vistas na Figura 5, abaixo:

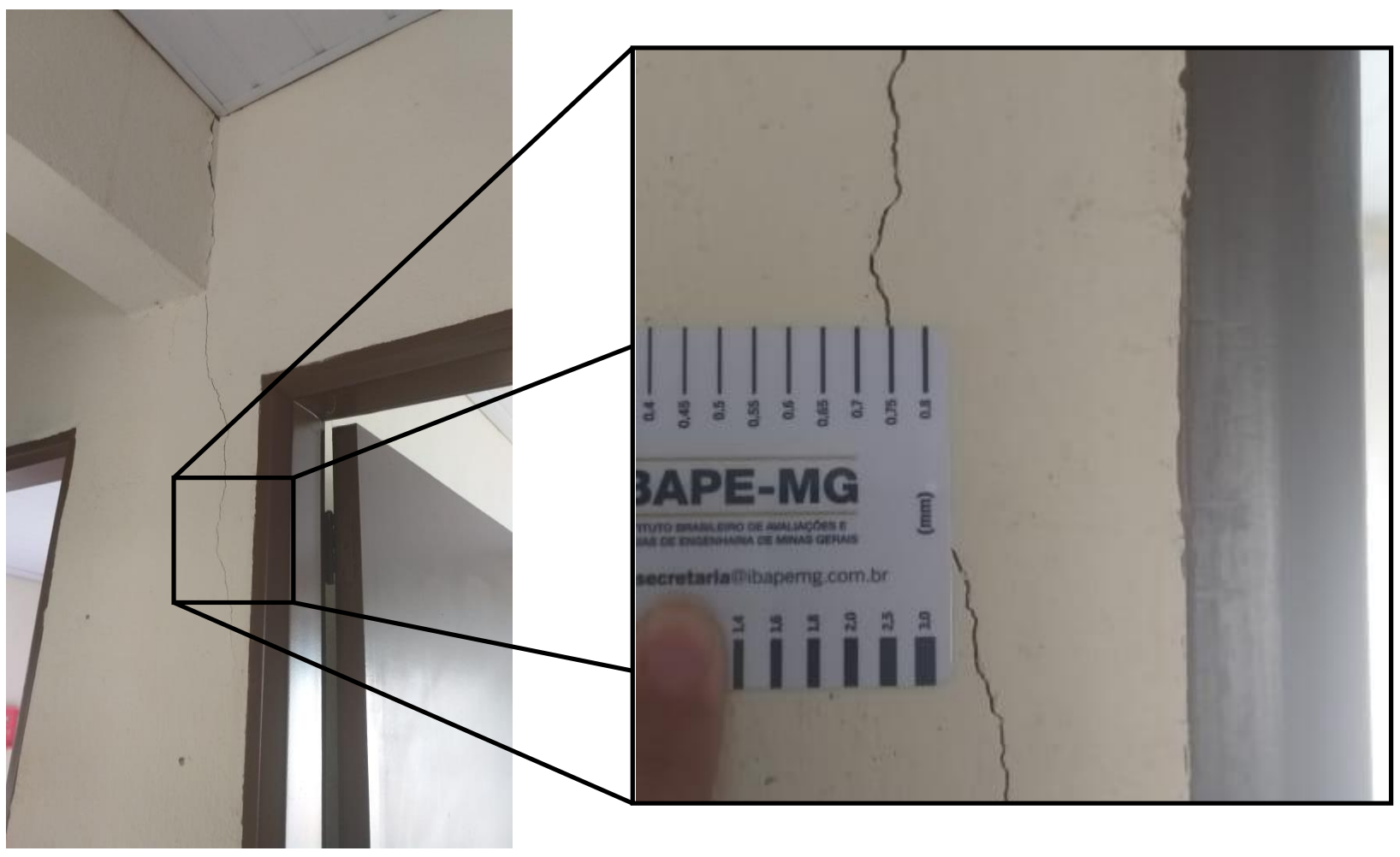

Figura 5: Localização da trinca, e detalhe da trinca, medida com um fissurômetro. Fonte: Acervo fotográfico dos autores. 
Logo acima do elemento construtivo existe uma caixa d'água e seu peso pode ter ocasionado as trincas na parede e viga, no entanto, os proprietários atrelam a anomalia com a atividade de uma pedreira que existia no bairro, que realizava explosões diárias. De acordo com os moradores, já foram feitos reparos corretivos com a inserção de armaduras, entretanto a anomalia se repetiu. Nota-se uma possível falta de verga na porta, pois a trinca entende para além do batente.

\subsubsection{Manchas de umidade na parede interna}

Foram encontradas manchas de umidade também em uma das paredes internas da casa, como visto na figura 6:

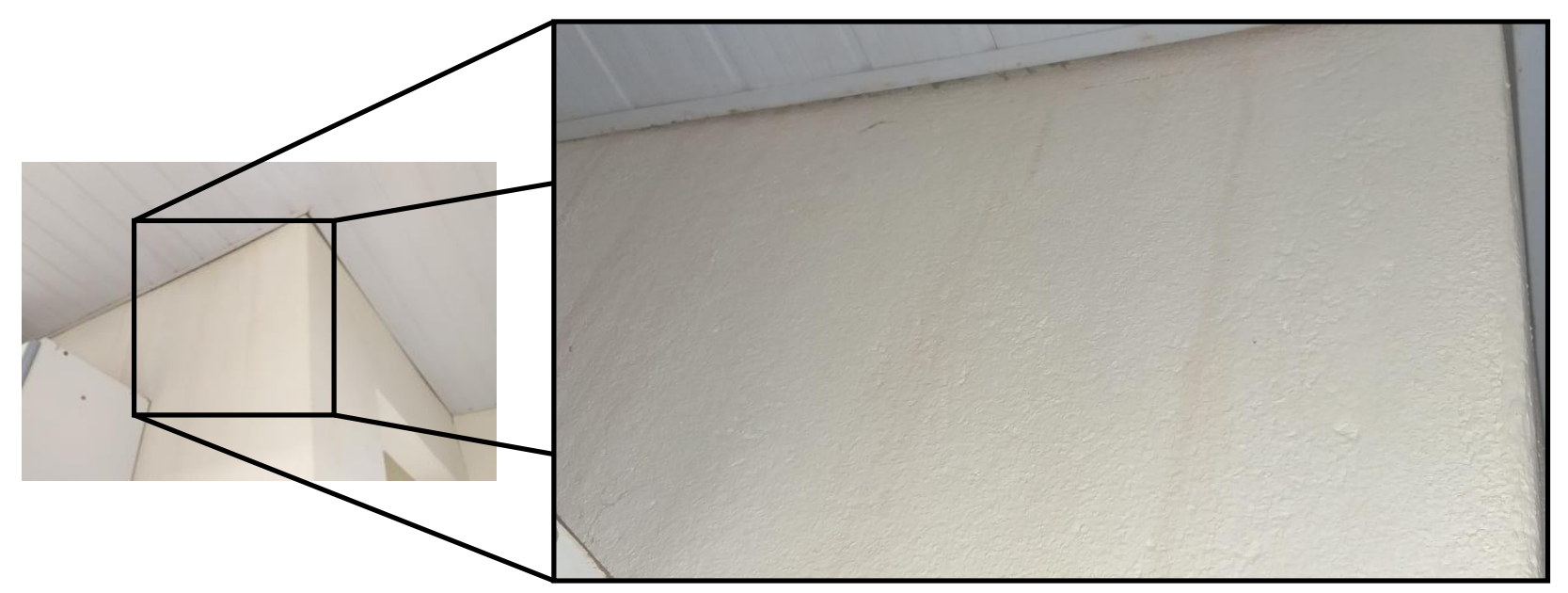

Figura 6: Parede que tem as manchas de umidade e detalhe da localização das manchas.

Fonte: Acervo fotográfico dos autores.

A mancha de umidade possivelmente ocorreu devido o vazamento de água pelas bordas da tampa da caixa d'água, o que fez surgir manchas características na parede adjacente ao corredor.

\subsection{Análise dos dados segundo a metodologia GUT}

As anomalias encontradas foram classificadas de acordo com os índices expostos na Tabela 2, tendo seus respectivos pesos definidos. Pelo cálculo do produto desses pesos determinou-se a prioridade em ordem decrescente do valor obtido, os quais foram inseridos na tabela abaixo:

Tabela 2 - Classificação GUT e determinação da ordem de prioridade.

\begin{tabular}{c|c|c|c|c|c}
\hline Elemento & $\begin{array}{c}\text { Gravidade } \\
\text { (a) }\end{array}$ & $\begin{array}{c}\text { Urgência } \\
\text { (b) }\end{array}$ & $\begin{array}{c}\text { Tendência } \\
\text { (c) }\end{array}$ & $\begin{array}{c}\text { Peso total } \\
\text { (a x b x c) }\end{array}$ & $\begin{array}{c}\text { Ordem de } \\
\text { prioridade }\end{array}$ \\
\hline $\begin{array}{c}\text { Infiltração no } \\
\text { muro e parede } \\
\text { externa }\end{array}$ & 3 & 10 & 8 & 240 & $2^{\circ}$ \\
\hline $\begin{array}{c}\text { Oxidação do } \\
\text { portão }\end{array}$ & 3 & 6 & 6 & 108 & $4^{\mathbf{0}}$ \\
\hline $\begin{array}{c}\text { Oxidação das } \\
\text { terças }\end{array}$ & 6 & 6 & 6 & 216 & $3^{\circ}$ \\
\hline $\begin{array}{c}\text { Trincas na } \\
\text { parede do } \\
\text { corredor }\end{array}$ & 6 & 10 & 6 & 360 & $1^{\mathbf{0}}$ \\
\hline $\begin{array}{c}\text { Manchas de } \\
\text { umidade na } \\
\text { parede interna }\end{array}$ & 1 & 3 & 3 & 9 & $5^{\circ}$ \\
\hline
\end{tabular}

Fonte: Autores. 
Após a análise de cada anomalia e da ordem de prioridade foi elaborada a Tabela 3, contendo as recomendações técnicas para sanar os efeitos dessas manifestações patológicas.

Tabela 3 - Recomendações técnicas feitas para cada uma das anomalias.

\begin{tabular}{|c|c|c|}
\hline Elemento & Ordem de prioridade & Recomendação técnica \\
\hline $\begin{array}{c}\text { Trincas na parede do } \\
\text { corredor }\end{array}$ & $1^{\circ}$ & $\begin{array}{c}\text { Recomendar-se-ia a inserção de armaduras para reforço da } \\
\text { estrutura, contudo, foram recebidas informações de que essa } \\
\text { providência já havia sido tomada, tendo o problema ainda assim } \\
\text { persistido; uma alternativa é a construção de uma estrutura externa } \\
\text { de suporte para a caixa d'água }\end{array}$ \\
\hline $\begin{array}{l}\text { Infiltração no muro e } \\
\text { parede externa }\end{array}$ & $2^{\circ}$ & $\begin{array}{c}\text { Implementar um sistema de drenagem (na face que confronta com } \\
\text { o vizinho) para que o acúmulo de água diminua e realizar a } \\
\text { instalação de calhas. }\end{array}$ \\
\hline Oxidação das terças & $3^{\circ}$ & $\begin{array}{c}\text { Devido ao custo relativamente alto, e ao poder econômico do } \\
\text { proprietário do imóvel, a limpeza e pintura dessas peças se torna } \\
\text { inviável, no entanto, o mesmo foi orientado da importância e } \\
\text { urgência da manutenção corretiva. }\end{array}$ \\
\hline Oxidação do portão & $4^{\circ}$ & $\begin{array}{c}\text { Realizar a limpeza com o auxílio de uma lixa, e a pintura do } \\
\text { portão com zarcão e tinta para evitar que a corrosão aumente e } \\
\text { cause danos maiores. }\end{array}$ \\
\hline $\begin{array}{l}\text { Manchas de umidade } \\
\text { na parede interna }\end{array}$ & $5^{\circ}$ & $\begin{array}{l}\text { Verificar a caixa d'água para definir e corrigir o problema } \\
\text { (melhorar a vedação), ou trocá-la, caso necessário. }\end{array}$ \\
\hline
\end{tabular}

Fonte: Autores.

\section{CONCLUSÕES}

Como esperado, foi possível detectar algumas anomalias, as quais foram causadas provavelmente por deficiência de projeto, e possivelmente pela utilização de materiais de baixa qualidade. O objetivo proposto foi alcançado na inspeção, e foi possível notar os tipos de manifestações patológicas recorrentes em edificações como a estudada.

As principais anomalias observadas foram trincas, infiltração e oxidação, problemas relativamente comuns em grande parte das residências. É importante que se realizem manutenções periódicas em qualquer edificação, para que problemas comuns como estes não se tornem falhas mais graves.

Propõe-se a realização de inspeções prediais, como a realizada neste estudo de caso, em outras edificações habitacionais, como as casas autoconstruídas e as casas de programas sociais, edificadas por diferentes construtoras. Com este estudo mais abrangente será possível a criação de um quadro comparativo das principais manifestações patológicas encontradas, e, porventura, a determinação dos principais problemas que levam ao aparecimento dessas anomalias.

\section{AGRADECIMENTOS}

Agradecemos ao Centro Federal de Educação Tecnológica de Minas Gerais - CEFET-MG pelo apoio direto e indireto a este trabalho e também aos proprietários da residência inspecionada por permitirem a realização deste estudo e por se colocarem a disposição para auxiliar em qualquer questão necessária. Também agradecemos ao apoio do LAR Laboratório de Avaliação e Reabilitação de Ambiente Construído do CEFET-MG - Campus Curvelo e a equipe do Projeto de Extensão "Inspeção predial e análise de anomalias e falhas construtivas em edificações" pelo incentivo a este trabalho.

\section{REFERÊNCIAS}

APOLONIO, P.; BERTULINO, T.; LINS, A. Inspeção predial: estudo de caso em uma habitação unifamiliar. In: Conferência Nacional de Patologia e Recuperação de Estruturas, I, 2017, Recife, Anais... Recife: 2017.

ASSOCIAÇÃO BRASILEIRA DE NORMAS TÉCNICAS. NBR 5674: Manutenção de edificações - Procedimento. Rio de Janeiro, 2012. 
ASSOCIAÇÃO BRASILEIRA DE NORMAS TÉCNICAS. NBR 15575: Edificações Habitacionais - Desempenho Parte 1: Requisitos gerais. Rio de Janeiro, 2013.

DIAS, S. C., BARROS, H. E. B., SOUSA, J. N., OLIVEIRA, B. N. C. A importância das inspeções prediais na redução de patologias: estudo de caso em Teresina-PI. $6^{a}$ Conferência sobre Patologia e Reabilitação de Edifícios PATORREB 2018, Cidade Universitária da UFRJ, Rio de Janeiro, Brasil.

INSTITUTO BRASILEIRO DE AVALIAÇÕES E PERÍCIAS DE ENGENHARIA. Norma de Inspeção Predial Nacional, 2012.

INSTITUTO BRASILEIRO DE AVALIAÇÕES E PERÍCIAS DE ENGENHARIA. Inspeção Predial: "a saúde dos edifícios". 2. Ed. São Paulo, 2012.

FREEBAY, GREGG A. Bridge Inspection Manual. Texas Department of Transportation. 2013. 147p.

NEVES, D. R. R.; BRANCO, L. A. M. N. Estratégia de inspeção predial. Belo Horizonte: Construindo, 2009, v.1, n.2, p.12-19.

NOGUEIRA, C. Inspeções periódicas nas pontes do Recife. Revista do Tribunal de Contas de Pernambuco, v. 14, n 14 (p. 114 e 115), Recife, PE, Brasil, 2003.

NOVELLO, B. S. Estudo de caso de construção habitacional comunitária para baixa renda na cidade do rio de janeiro. 2018. 119 f. Monografia (Graduação em Engenharia Civil) - Escola Politécnica da Universidade Federal do Rio de Janeiro, Rio de Janeiro, RJ, Brasil, 2018.

PACHECO, L. S. Contribuição ao estudo de sistemas de inspeção e conservação predial: levantamento de boas práticas e identificação de padrões de deterioração com base na análise de dados de laudos de inspeção. 2017. 177 f. Tese (Doutorado em Engenharia Civil) - Escola de Engenharia da Universidade Federal do Rio Grande do Sul, Porto Alegre, RS, Brasil, 2017.

POSSAN, E.; DEMOLINER, C. A. Desempenho, durabilidade e vida útil das edificações: abordagem geral. Paraná: Revista Técnico-Científica do Crea-PR, 2013.

ROMÉRO, M.; ORNSTEIN, S. Avaliação pós-ocupação: Métodos e Técnicas Aplicados à Habitação Social. Coleção HABITARE/FINEP. Porto Alegre, 2003.

SILVA, L. W. Inspeção predial: diretrizes, roteiro e modelo de laudo para inspeções em edificações residenciais da cidade do Rio de Janeiro. 2016. 138 f. Monografia (Graduação em Engenharia Civil) - Escola Politécnica da Universidade Federal do Rio de Janeiro, Rio de Janeiro, RJ, Brasil, 2016. 